\title{
High occurrence of head and spine injuries in the pediatric population following motocross accidents
}

\author{
David J. Daniels, MD, PhD, ${ }^{1}$ Michelle J. Clarke, MD, ${ }^{1}$ Ross Puffer, MD,, T. David Luo, MD, ${ }^{2}$ \\ Amy L. Mclntosh, MD, ${ }^{2}$ and Nicolas M. Wetjen, MD' ${ }^{1}$
}

Departments of ${ }^{1}$ Neurosurgery and ${ }^{2}$ Orthopaedic Surgery, Mayo Clinic College of Medicine, Mayo Clinic, Rochester, Minnesota

OBJECT Off-road motorcycling is a very popular sport practiced by countless people worldwide. Despite its popularity, not much has been published on the severity and distribution of central nervous system-related injuries associated with this activity in the pediatric population. The purpose of this study was to confirm, characterize, and document the rate of head and spine injuries associated with off-road motorcycling in this population.

METHODS All patients aged 18 years or less who were treated for a motorbike injury at the authors' institution (a Level 1 regional trauma center) between 2000 and 2007 were identified through in-house surgical and trauma registries. Type, mechanism, and severity of CNS-related injuries were assessed, including: incidence of traumatic brain injury (TBI), loss of consciousness (LOC), Glasgow Coma Scale (GCS) score, head CT findings, neurological deficits, spinal fractures, cervical strain, and use of protective gear, including helmets.

RESULTS During the 8-year period of study, 298 accidents were evaluated in 248 patients. The patients' mean age at the time of injury was $14.2 \pm 2.7$ years. Head injury or TBI was identified in $60(20.1 \%)$ of 298 cases (involving 58 of 248 patients). Fifty-seven cases were associated with LOC, and abnormalities were identified on head CT in 10 patients; these abnormalities included skull fractures and epidural, subdural, subarachnoid, and intraparenchymal hemorrhages. The GCS score was abnormal in 11 cases and ranged from 3 to 15, with an overall mean of 14.5. No patients required cranial surgery. Helmet use was confirmed in 43 (71.6\%) of the cases involving TBI. Spine fractures were identified in 13 patients (4.3\%) and 5 required surgical fixation for their injury.

CONCLUSIONS The authors found a high occurrence of head injuries following pediatric off-road motorcycle riding or motocross accidents despite the use of helmets. Additionally, this study severely underestimates the rate of mild TBls in this patient population. Our data indicate that motocross is a high-risk sport despite the use of protective gear. Riders and parents should be counseled accordingly about the risks prior to participation.

http://thejns.org/doi/abs/10.3171/2014.9.PEDS14149

KEY WORDS motocross; motorcycle; pediatric; sports injury; trauma

$\mathrm{S}$ PORTS are a major cause of traumatic brain injuries (TBIs) in the pediatric population. Conservatively, it is estimated that over 300,000 sport-related TBIs occur annually in the United States, although this figure only includes patients who suffer a loss of consciousness (LOC). ${ }^{19,20,22,32,33}$ More likely, 1.6-3.8 million sport-related TBIs occur worldwide, ${ }^{4,19,30}$ with an estimated $90 \%$ of sport-related concussions going unidentified. ${ }^{34}$ Emergency department visits for sport-related TBIs in the pediatric population have increased $60 \%$ in the past decade. ${ }^{9}$ The highest rate of emergency room visits for sport-related concussion occur in the 10- to 14-year age group, ${ }^{10}$ and concussion accounts for more than $10 \%$ of athletic injuries in high school athletes. ${ }^{14,25}$ The long-term consequences of traumatic brain injury in the pediatric population is currently unknown, and recently all 50 states have passed laws surrounding "return to sports" following sport-related concussions.

Although it is well recognized that high-impact sports such as football and hockey are associated with a high incidence of head and spinal injuries, not much is known about the pediatric injury patterns associated with 2 -wheel motorbike use. Since the 1960s, miniature motorcycles have been marketed to children for recreational and competitive use. ${ }^{1}$ Motocross racing is a popular sport organized by the American Motorcyclist Association that includes specific

ABBREVATIONS ASIA = American Spinal Injury Association; ATV = all-terrain vehicle; CN = cranial nerve; GCS = Glasgow Coma Scale; LOC = loss of consciousness; TBI

$=$ traumatic brain injury.

SUBMITTED March 20, 2014. ACCEPTED September 8, 2014.

INCLUDE WHEN CITING Published online January 2, 2015; DOI: 10.3171/2014.9.PEDS14149.

DISCLOSURE The authors report no conflict of interest concerning the materials or methods used in this study or the findings specified in this paper. 
events for riders 4 years of age and up. ${ }^{2}$ Regulation varies by state. In Minnesota, there are laws protecting children and adolescents using 2-wheel off-road motorcycles. These include mandatory eye protection for all riders, mandatory helmet use for those under 18 years of age, rider education certification for those under 16 years of age, and direct adult supervision for those under 12 years of age (http:// www.americanmotorcyclist.com).

Two populations of pediatric motorcyclists have been studied. Over a 6-year period in Ohio, 6 participating hospitals admitted 182 children suffering from injuries sustained while operating a motorbike. They reported that $22 \%$ of the hospitalized patients suffered a head injury, but further details were not specified. ${ }^{29}$ In Minnesota, our collaborators have published 2 reports on pediatric motocross injuries. ${ }^{16,21}$ The first looked at the range of injuries and overall economic burden in a group of 248 patients who presented to the emergency department following motocross accidents. The second study looked at the various truncal injuries sustained. Neither of the 2 studies focused on CNS-related injuries. Thus, there are currently limited available data in regards to head and spine injuries sustained by pediatric patients while operating a motorcycle or participating in motocross.

Within our regional catchment area, there are 7 competition motocross courses. Due to our rural location, injuries from these tracks are most commonly referred to our tertiary care center. ${ }^{16,21}$ The purpose of this study is to determine the type, severity, and modifying factors of head and spine injuries sustained by competitive and recreational pediatric motocross riders.

\section{Methods}

This is a retrospective population-based cohort study that was approved by the Mayo Clinic institutional review board. The study population consisted of patients aged 18 years or less who were treated for a motorbike/motocross injury at our Level 1 trauma facility between 2000 and 2007. This is an overlapping cohort that was included in our recent studies investigating the orthopedic injuries and economic cost of pediatric motocross accidents. ${ }^{16,21} \mathrm{~A}$ motorbike was defined as a " 2 -wheeled vehicle that was designed for off-road use" 21 and included dirt bikes, minibikes, and miniature motorcycles. The patient had to be operating a motorbike either for recreational or competitive use on a closed course or private property. Passengers or pedestrians hit by a motorbike, as well as patients injured in accidents involving all-terrain vehicles (ATVs), were excluded from this study.

Patients were identified through our institution's medical, surgical, and trauma databases, which track all trauma hospital admissions and Level 1 and 2 traumas evaluated in our emergency department. Demographic and accidentrelated data including age, sex, location of accident, and use of helmet were collected. The records were reviewed for injury type, LOC, Glasgow Coma Scale (GCS) score, neurological examination findings, imaging abnormalities on head and spine CT scans, days of hospitalization, and need for surgery. TBI or head injury was defined as a positive LOC (confirmed LOC) or a head CT abnormality.

\section{Results}

We identified 298 injuries in 248 unique patients during the study period (Table 1). Of these patients, 231 (93.1\%) were male. The patients' mean age was 14.2 years (range 5.4-17.9 years, SD 2.7). Of the patients studied, 95\% lived within the catchment region. The majority of injuries occurred at one of the 7 local motocross tracks, with 184 patients injured at a track $(61.7 \%)$ and about half (151 [50.7\%]) of the injuries occurring during competition. The remaining patients were injured on private property or at an unverifiable location (Table 1). Helmet use was recorded in 165 injury episodes (55.4\%), with 155 (94\%) of the patients wearing a helmet at the time of injury.

Head injury type is outlined in Table 2. Head injury or TBI occurred in 60 (20.1\%) of 298 injuries, with $95 \%$ (57 of 60) of these patients suffering a concussion with LOC. The patients' earliest recorded GCS score averaged 14.5 (range 3-15). Four patients presented with neurological deficits $(6.6 \%$ overall) - hemiparesis, hemianesthesia, cranial nerve (CN) III palsy, and paraplegia (from spinal cord injury). In 83 (28\%) of the 298 injury episodes, the workup included CT scans. Of the 60 patients with head injuries, 10 (representing $3.4 \%$ of our overall patient group) had abnormal head CT findings, including skull fractures (5 patients), epidural hematoma (1 patient), subdural hematoma (3 patients), subarachnoid hemorrhage (5 patients), intraparenchymal hemorrhage (1 patient), and diffuse axonal injury (1 patient). Forty (66.7\%) of the patients with a head injury were admitted to the hospital. Two patients were admitted with significant head injuries and LOC of more than 30 minutes. Of these patients, one was able to return to school and noncontact sports 3 years following injury. The second patient had prolonged hemiparesis and was able to return to school 18 months following injury. A third patient had a persistent CN III palsy. All of the patients with neurological deficits were wearing helmets and were participating in formal competition at the time of their accident. Of the 60 patients with head injuries, $40(66.7 \%)$ were confirmed to be wearing their helmet at the time of accident, and $3(5 \%)$ admitted to no hel-

TABLE 1. Demographic characteristics of patients and sites of injuries

\begin{tabular}{lc}
\hline \multicolumn{1}{c}{ Characteristic } & Value $^{*}$ \\
\hline Total no. of injuries & 299 \\
\hline No. of unique patients & 248 \\
\hline Male & $231(93.1 \%)$ \\
\hline Female & $17(6.9 \%)$ \\
\hline Age & 14.2 years \\
\hline Live in region & $95 \%$ \\
\hline Site of injury & $184(61.7 \%)$ \\
\hline Formal motocross course & $151(50.7 \%)$ \\
\hline In competition & $53(17.8 \%)$ \\
\hline Private property & $61(20.5 \%)$ \\
\hline Unknown location
\end{tabular}

* Values indicate numbers of patients or injuries (\%) unless otherwise indicated. 
TABLE 2: Neurological injuries and helmet use

\begin{tabular}{lc}
\hline \multicolumn{1}{c}{ Description } & Value $^{*}$ \\
\hline No. of injuries & 298 \\
\hline No. of head injuries/TBIs & $60(20.1 \%)$ \\
\hline LOC & $57(19.1 \%)$ \\
\hline Abnormality on head CT† & $10(3.4 \%)$ \\
\hline GCS score & 14.5 \\
\hline Mean & $3-15$ \\
\hline Range & $4(1.3 \%)$ \\
\hline Neurological deficit & $40(66.7 \%) \ddagger$ \\
\hline No. of hospital admissions for head injury & \\
\hline Helmet use§ & $43(71.7 \%)$ \\
\hline Confirmed & $3(5 \%)$ \\
\hline None & $14(23.3 \%)$ \\
\hline Unknown & $13(4.4 \%)$ \\
\hline Spine injury & $1(0.3 \%)$ \\
\hline Fractures & $9(3.0 \%)$ \\
\hline SCl
\end{tabular}

$\mathrm{SCl}=$ spinal cord injury .

* Values represent numbers injuries (\%) unless otherwise indicated.

$\dagger$ Includes skull fractures, epidural, subdural, subarachnoid and intraparenchymal hemorrhages, and diffuse axonal injury.

$\ddagger$ Percentage of head injuries.

$\S$ For patients with head injuries. Percentages are based on number of head injuries $(n=60)$.

met use. The remaining patients did not have helmet use documented at the time of accident. All patients riding at a formal motocross course were helmeted. Of note, 50 patients $(20.1 \%)$ presented to the emergency department for 2 separate motocross accidents, and 4 of these patients had repeat head injuries.

Spine fractures were found in 13 (4.4\%) of 298 injuries and included transverse process fractures (5 patients), and thoracic or lumbar compression/burst fractures (11 patients). Surgical stabilization of the spine was required in 5 cases. Cervical strain was diagnosed in 9 patients $(3.0 \%)$ and treated with a cervical collar, but no cervical fractures were identified. One patient presented with a complete spinal cord injury (paraplegia) from a T-5 burst fracture with disc retropulsion, but after surgical decompression and extensive inpatient/outpatient therapy, the patient's condition improved and 1 year after the accident, the injury classification on the American Spinal Injury Association (ASIA) Impairment Scale was ASIA D .

\section{Discussion}

Sport-related TBI has been garnering greater attention, including professional and amateur sport league rule changes as well as increased attention to diagnosis and treatment of TBI and the impact on young athletes. ${ }^{31}$ In 2009, the state of Washington became the first state to pass a law regarding concussion management in children, but recently all 50 states have adopted similar types of legislation surrounding concussion management in youth athletes. Most of these laws require school boards and state athletic associations to develop and provide educational materials and guidelines for athletes, coaches, and parents surrounding concussions in sports. Moreover, most states require a physician or licensed health care professional to give the final return-to-play clearance following a sport-related concussion. We suspect that the majority of patients with mild concussions from motocross accidents are never seen by a physician or cleared for return to play.

Despite all this attention, sports like motocross, in which high-velocity impacts can be expected, continue to gain in popularity. Using the National Electronic Injury Surveillance System All-Injury Program (NEISS-AIP), the Centers for Disease Control (CDC) estimates that 23,800 off-road motorcyclists under 19 years of age were treated in US hospitals for nonfatal injuries from 2001 to $2004 .{ }^{5}$ Additionally, there was a $33.7 \%$ increase in injury rate from 2001 to 2004, although it was not deemed statistically significant. ${ }^{5}$ Although age-stratified data on participation in motocross are not available, the sport itself has grown, as evidenced by off-road-capable motorcycle sales, which have almost doubled from 1999 to the 300,000 bikes sold in 2003.?

There is little information on overall injury rates in the pediatric population involved in motorsports. The first major studies involved ATV riders: In 2005, there were 804 deaths attributable to ATVs, with 163 of the decedents being children, and 136,700 emergency room-treated injuries, of which $30 \%$ occurred in children, according to a Consumer Product Safety Commission report published in $2010 .{ }^{6}$ In a study based on the Kids' Inpatient Database and published in 2005, Killingsworth et al. reported that 2600 admissions were due to ATVs over a 3-year period. ${ }^{17}$ Based on injury patterns in 3- and 4-wheeled ATVs and other safety concerns, the sale of 3-wheeled ATVs was banned in 1988, and the American Academy of Pediatrics recommends that no 2- or 4- wheeled off-road vehicle be ridden by a child under 16 years of age. Furthermore, the Consumer Product Safety Commission recommends that children be restricted to an ATV engine size of less than $90 \mathrm{cc}$. Similar formal recommendations for motorbike use are absent.

Three studies of motocross morbidity in children outline the seriousness of these injuries. In the Ohio study, in 182 patients presenting to the emergency department following a motorbike crash, there were 510 injuries, with $68.7 \%$ of patients sustaining multiple injuries. Of these patients, 1 patient died, 8 patients required rehabilitation. The median length of hospital stay was 4.6 days (range less than 1 day to 100 days), although no specific details regarding head injuries were included. ${ }^{29}$ In the Minnesota study, our collaborators looked at the overall injury patterns and economic cost of motocross injuries in children. In the 299 injury episodes, 141 patients $(56.6 \%)$ were admitted to the hospital (20 via intensive care unit) with a mean length of stay of 2.9 days (range 1-29 days). Surgery was required in 91 cases (36.5\%), and a significant amount of orthopedic injuries $(95.0 \%)$ were identified. The mean charges per hospitalization ranged from $\$ 105$ to $\$ 217,780$, for a total cost of $\$ 4.5$ million. ${ }^{21}$ Another study looked at the truncal injuries sustained during formal motocross 
racing. In 162 accidents that presented to our emergency department, 30 patients $(18.5 \%)$ were found to have abdominal or thoracic injuries, and 27 of these patients required surgery. The most common injuries were pneumothorax, pulmonary contusions, and splenic or hepatic lacerations.

A recent report by the American Academy of Pediatrics suggests that only $10 \%$ of patients with concussions have a positive LOC. In our study, $95 \%$ of patients diagnosed with head injury had a positive LOC at the time of accident. Although it is possible that the speed and high impact forces generated in a motocross crash may lead to patients having a higher incidence of LOC than in other sports, it is likely that mild and moderate concussions are simply not being captured in this analysis. Thus, it is likely that this study significantly underreports the incidence of TBI in pediatric motocross riders. Furthermore, we suspect that most children with concussions following motocross accidents are not evaluated by a physician or properly given return-to-play clearance as mandated by current legislation in sanctioned high school sports. This realization has prompted our group to survey riders from a local motocross race track directly to determine the incidence of unreported TBI. ${ }^{24}$ Our investigation determined that nearly half of the riders surveyed reported concussion symptoms, yet over $60 \%$ of those riders continued riding on the same day, supporting our theory that we are not capturing all injuries and mild and moderate head injuries are not being appropriately evaluated and treated.

Observational studies have demonstrated that motorcycle helmet use reduces the risk of death and head injury ${ }^{15,23,28}$ and lowers hospital charges in the event of a motorcycle accident. ${ }^{3,27}$ The largest evidence comes from a meta-analysis of 61 observational studies demonstrating a $42 \%$ decreased incidence of death and a $69 \%$ decreased incidence of head injury with motorcycle helmet use. ${ }^{23}$ Such information is lacking in the pediatric population, but the importance of helmet use in motocross riding can be extrapolated from other activities that can involve cranial impact, such as bicycle riding. ${ }^{26}$ It appears that this information has permeated the motocross community: in our study, only $5 \%$ of riders with head injuries were confirmed to have not been wearing helmets. In contrast, despite helmet use being universally known as a safety precaution, it is estimated that only $15 \%-25 \%$ of children wear helmets while riding bicycles. ${ }^{26}$ Although the acceptance of safety equipment should be applauded, the severity and frequency of injury despite helmet use underscores the dangers of motocross riding.

There are two other published studies specifically looking at motocross injury patterns. The first was out of Southern California and reviewed 270 motocross injuries in patients who presented to the emergency department, but it included few children..$^{2}$ The authors found a high rate of head injury (88 injuries [33\%]) in this mostly adult population, with the majority of the patients with head injuries presenting with concussion. They also found a high occurrence of spine fractures (24 fractures [9\% of injuries]) that was about twice as much as in our study and one patient had a spinal cord injury. In a large study out of Europe that looked at motocross injuries in professional motocross racers during International Motorcycle Federation races, a high incidence of head injury was also observed. ${ }^{11}$ The authors reported only $5.7 \%$ of accidents were associated with a head injury but state that, in the 1500 accidents, $16.3 \%$ had a positive LOC-which is similar to our findings. They found a $2 \%$ occurrence of spine fractures, and $0.5 \%$ of accidents resulted in a spinal cord injury. Other studies also indicate that spine injuries are relatively rare, comprising only $5.8 \%$ of reported fractures, but they are often severe, with one-third of patients suffering permanent neurological damage..$^{13}$ Since the publication of these studies involving predominantly adult cohorts, attention to spine injury prevention has increased and cervical spine protection equipment, such as the HANS device (http:// hansdevice.com/Home.html), has increased in popularity. Nevertheless, it remains to be seen if use of this expensive equipment trickles down to younger riders or if there is a major impact on injury rates. ${ }^{8}$

While the present study provides a unique perspective due to the near-captive patient population our rural tertiary care center offers, there are major limitations, especially in estimating the number of patients at risk for trauma and therefore the overall rate of severe injury. ${ }^{24}$ That said, the growing popularity of motocross and the young age of participants necessitates evaluation of safety procedures to reduce the risk of head injury among participants. ${ }^{18,34}$ Sadly, many states have no regulations involving children and adolescents riding off-road motorcycles. ${ }^{29,34}$ Helmets should be mandatory in all states for pediatric motorsport participants. Education should be mandatory and should include explicit details on the risk of serious injury and death and instruction in helmet use, as well as rider training. Restrictions on the purchase of these small motorcycles should be discussed at the legislative level, although the likelihood of banning sales is low. ${ }^{29}$ At the very least, physicians need to be aware of the risks and promote responsible riding among their patients.

\section{Conclusions}

Motocross riding in the pediatric population is a growing sport and thus far the risks have been poorly defined. We note a high rate of TBI in pediatric motocross riders, but our data suggest that our findings greatly underestimate the true risk. While other studies conclusively demonstrate that helmet use decreases the risk of death and head injury, our study clearly demonstrates that helmet use does not eliminate these risks. Riders and parents need to be counseled accordingly about the risks of head injury prior to participation and in accordance with state laws. Furthermore, formal return-to-play guidelines following concussions need to be developed and supported by the American Motorcycle Association and by professional supercross and motocross participants.

\section{References}

1. American Academy of Pediatrics Committee on Accident and Poison Prevention: All-terrain vehicles: two-, three-, and four-wheeled unlicensed motorized vehicles. Pediatrics 79:306-308, 1987

2. American Motorcyclist Association: 2008 Rulebook: 
Governing Pro-Am, Standard, ATV and Youth Competition. (http://www.americanmotorcyclist.com/Libraries/ Racing_Documents/AmateurRules2008.sflb.ashx) [Accessed November 2, 2014]

3. Brandt MM, Ahrns KS, Corpron CA, Franklin GA, Wahl WL: Hospital cost is reduced by motorcycle helmet use. J Trauma 53:469-471, 2002

4. Collins MW, Iverson GL, Lovell MR, McKeag DB, Norwig J, Maroon J: On-field predictors of neuropsychological and symptom deficit following sports-related concussion. Clin J Sport Med 13:222-229, 2003

5. Conn J, Annest J, Paulozzi L: Nonfatal injuries from off-road motorcycle riding among children and teens-United States, 2001-2004. MMWR Morb Mortal Wkly Rep 55:621-624, 2006

6. Consumer Product Safety Commission: 2008 Annual Report of ATV-Related Deaths and Injuries. January, 2010. (https://www.cpsc.gov//PageFiles/108621/atv2008.pdf) [Accessed November 2, 2014]

7. Cordell HK, Betz CJ, Green G, Owens M: Off-Highway Vehicle Recreation in the United States, Regions and States: A National Report From the National Survey on Recreation and Environment (NSRE). June, 2005. US Forest Service. (http://www.fs.fed.us/recreation/programs/ohv/OHV_final_ report.pdf) [Accessed November 2, 2014]

8. Daniels DJ, Luo TD, Puffer R, McIntosh AL, Larson AN, Wetjen NM, et al: Degenerative changes in adolescent spines: a comparison of motocross racers and age-matched controls. J Neurosurg Pediatr [epub ahead of print January 2, 2015. DOI: 10.3171/2014.9.PEDS14153]

9. Faul M, Xu L, Wald MM, Coranado VG: Traumatic Brain Injury in the United States: Emergency Department Visits, Hospitalizations, and Deaths 2002-2006. Atlanta: Centers for Disease Control and Prevention, 2010 (http:// www.cdc.gov/traumaticbraininjury/pdf/blue_book.pdf) [Accessed November 2, 2014]

10. Gilchrist J, Thomas K, Xu L, McGuire L: Nonfatal traumatic brain injuries related to sports and recreation activities among persons aged $\leq 19$ years-United States, 2001-2009. MMWR Morb Mortal Wkly Rep 60:1337-1342, 2011

11. Gobbi A, Tuy B, Panuncialman I: The incidence of motocross injuries: a 12-year investigation. Knee Surg Sports Traumatol Arthrosc 12:574-580, 2004

12. Gorski TF, Gorski YC, McLeod G, Suh D, Cordero R, Essien F, et al: Patterns of injury and outcomes associated with motocross accidents. Am Surg 69:895-898, 2003

13. Grange JT, Bodnar JA, Corbett SW: Motocross medicine. Curr Sports Med Rep 8:125-130, 2009

14. Guerriero RM, Proctor MR, Mannix R, Meehan WP III: Epidemiology, trends, assessment and management of sportrelated concussion in United States high schools. Curr Opin Pediatr 24:696-701, 2012

15. Hooten KG, Murad GJ: Helmeted vs nonhelmeted: a retrospective review of outcomes from 2-wheeled vehicle accidents at a level 1 trauma center. Clin Neurosurg 59:126-130, 2012

16. Kennedy RD, Potter DD, Osborn JB, Zietlow S, Zarroug AE, Moir CR, et al: Childhood motocross truncal injuries: highvelocity, focal force to the chest and abdomen. BMJ Open 2:e001848, 2012

17. Killingsworth JB, Tilford JM, Parker JG, Graham JJ, Dick RM, Aitken ME: National hospitalization impact of pediatric all-terrain vehicle injuries. Pediatrics 115:e316-e321, 2005

18. Lace JK, Goldstein B: Kids and motorbikes: the need for speed. Pediatrics 115:1085-1086, 2005

19. Langlois JA, Rutland-Brown W, Thomas KE: Traumatic Brain Injury in the United States: Emergency Department Visits, Hospitalizations, and Death. Atlanta: Centers for Disease Control and Prevention, 2004

20. Langlois JA, Rutland-Brown W, Wald MM: The epidemiol- ogy and impact of traumatic brain injury: a brief overview. $\mathbf{J}$ Head Trauma Rehabil 21:375-378, 2006

21. Larson AN, Stans AA, Shaughnessy WJ, Dekutoski MB, Quinn MJ, McIntosh AL: Motocross morbidity: economic cost and injury distribution in children. J Pediatr Orthop 29:847-850, 2009

22. Levy ML, Kasasbeh AS, Baird LC, Amene C, Skeen J, Marshall L: Concussions in soccer: a current understanding. World Neurosurg 78:535-544, 2012

23. Liu BC, Ivers R, Norton R, Boufous S, Blows S, Lo SK: Helmets for preventing injury in motorcycle riders. Cochrane Database Syst Rev (1):CD004333, 2008

24. Luo TD, Clarke MJ, Zimmerman AK, Quinn M, Daniels DJ, McIntosh AL: Concussion symptoms in youth motocross riders: a prospective, observational study. J Neurosurg Pediatr [epub ahead of print January 2, 2015. DOI: 10.3171/2014.11. PEDS14127]

25. Marar M, McIlvain NM, Fields SK, Comstock RD: Epidemiology of concussions among United States high school athletes in 20 sports. Am J Sports Med 40:747-755, 2012

26. Mattei TA, Bond BJ, Goulart CR, Sloffer CA, Morris MJ, Lin JJ: Performance analysis of the protective effects of bicycle helmets during impact and crush tests in pediatric skull models. J Neurosurg Pediatr 10:490-497, 2012

27. Max W, Stark B, Root S: Putting a lid on injury costs: the economic impact of the California motorcycle helmet law. $\mathbf{J}$ Trauma 45:550-556, 1998

28. Missouri Center for Health Information Management and Epidemiology: Crash Outcome Data Evaluation System (CODES), 1993. Jefferson City, MO: CHIME, 1997

29. Pomerantz WJ, Gittelman MA, Smith GA: No license required: severe pediatric motorbike-related injuries in Ohio. Pediatrics 115:704-709, 2005

30. Schulz MR, Marshall SW, Mueller FO, Yang J, Weaver NL, Kalsbeek WD, et al: Incidence and risk factors for concussion in high school athletes, North Carolina, 1996-1999. Am J Epidemiol 160:937-944, 2004

31. Sills AK, Solomon G, Ellenbogen R: Commentary: The neurosurgeon in sport: an update from the 2012 Zurich International Concussion Conference. Neurosurgery 73:E1091E1098, 2013

32. Thurman D, Guerrero J: Trends in hospitalization associated with traumatic brain injury. JAMA 282:954-957, 1999

33. Thurman DJ, Branche CM, Sniezek JE: The epidemiology of sports-related traumatic brain injuries in the United States: recent developments. J Head Trauma Rehabil 13:1-8, 1998

34. Vane DW: Motorized vehicles for children: a new public health problem. Pediatrics 115:1087, 2005

\section{Author Contributions}

Conception and design: Clarke, Daniels, Puffer, Wetjen. Acquisition of data: Daniels, Puffer. Analysis and interpretation of data: Clarke, Daniels, Puffer. Drafting the article: Clarke, Daniels, Puffer, Luo. Critically revising the article: Clarke, Daniels, Puffer, Luo, McIntosh. Reviewed submitted version of manuscript: all authors. Approved the final version of the manuscript on behalf of all authors: Clarke. Statistical analysis: Daniels, Puffer. Administrative/technical/material support: Clarke, McIntosh, Wetjen. Study supervision: McIntosh, Wetjen.

\section{Correspondence}

Michelle J. Clarke, Department of Neurologic Surgery, Mayo Clinic, 200 First St. SW, Rochester, MN 55905. email: clarke. michelle@mayo.edu. 